\title{
Drosophila suzukii (Diptera: Drosophilidae) Oviposition and Adult Emergence in Six Wine Grape Varieties Grown in Virginia
}

\author{
Meredith Edana Shrader, ${ }^{1,4}$ Hannah J. Burrack, ${ }^{2}$ and Douglas G. Pfeiffer ${ }^{3}$
}

'Colorado State University Extension, Grand Junction, CO 81503, 2Department of Entomology, North Carolina State University, Raleigh, NC 27607, 3Department of Entomology, Virginia Polytechnic Institute and State University, Blacksburg, VA 24061, and ${ }^{4}$ Corresponding author, e-mail: meredith.shrader@mesacounty.us

Subject Editor: Anthony Clarke

Received 12 April 2018; Editorial decision 5 September 2018

\begin{abstract}
Drosophila suzukii (Matsumura) is a pest of small fruits and grapes in the United States and in its home range of Japan. Physiological and morphological laboratory testing was performed on six commonly grown wine grape varieties inVirginia. Skin thickness, penetration force, and ${ }^{\circ}$ Brix were analyzed to determine ovipositional preferences. Experiments were performed for three consecutive years from grapes collected at one Virginia vineyard. More eggs were laid in intact Viognier grapes than any other variety. Oviposition into intact grapes was not affected by skin thickness or ${ }^{\circ}$ Brix; however, oviposition increased when penetration force decreased. An ovipositional choice test determined no varietal preferences. Survivorship from egg to adulthood using uninjured and injured grapes was also assessed to determine varietal suitability as $D$. suzukii hosts, with more flies emerging from injured grapes than uninjured. However, D. suzukii adults did emerge from intact grapes and at higher percentages than previously recorded in other wine grape studies. All varieties had eggs oviposited into them when injured. Determining the time at which each grape variety became susceptible to oviposition was determined using a D. suzukii bioassay spanning $12 \mathrm{wk}$ using grapes from the green pea stage until ripe. Susceptibility to $D$. suzukii oviposition was based upon ripening period and penetration force. Early ripening varieties may be more susceptible to $D$. suzukii oviposition in the field with later maturing, harder fleshed-varieties which may escape $D$. suzukii oviposition.
\end{abstract}

Key words: wine grape, penetration force, susceptibility, survivorship, skin thickness

Drosophila suzukii (Matsumura) (Diptera: Drosophilidae), spottedwing drosophila, is economically damaging to small fruits, cherries, and grapes in areas where these crops are produced (Goodhue et al. 2011, Walsh et al. 2011). D. suzukii can develop in both wild and cultivated grapes, including both table and wine grapes (Ioriatti et al. 2015, Kim et al. 2015). The serrated ovipositor of female D. suzukii facilitates oviposition in ripening fruit that other drosophilid species cannot utilize (Lee et al. 2011a). Larvae developing within the fruit reduce fruit quality and marketability (Walsh et al. 2011). Furthermore, female D. suzukii can render grapes susceptible to secondary pathogens, such as Acetobacter spp., Gluconobacter spp., and Hanseniaspora uvarum, and facilitate sour rot outbreaks in vineyards through piercing and wounding the fruit during oviposition (Barata et al. 2012, Hamby and Becher 2016). If sour rot is found in a few grapes within a cluster, the whole cluster may be culled. In addition to the loss of individual clusters in the field, sour rot in grapes can cause whole packing crates of grapes to be rejected by processors and wine makers.
Grapes are suitable hosts for D. suzukii. In Japan, Kanzawa (1939) demonstrated that $D$. suzukii reared on grapes had larger pupae than those reared on cherries. However, recent studies have shown that D. suzukii lay fewer eggs in grapes and have a longer developmental time and lower survivorship, 0-9\%, compared with larva that develop in other fruits, such as raspberries and cherries (Lee et al. 2011b). Relative ranking of crop hosts suggest that grapes are poor hosts for D. suzukii (Bellamy et al. 2013), however, flies are able to complete their life cycle on this fruit. D. suzukii ovipositional preferences have been linked to fruit characteristics such as fruit firmness and ${ }^{\circ}$ Brix, with more D. suzukii eggs being laid in fruit with low penetration force and higher ${ }^{\circ}$ Brix (Burrack et al. 2013, Ioriatti et al. 2015). It may be possible to determine if certain varieties are at greater risk of D. suzukii infestations based upon the morphological and physiological characteristics for each grape variety within a vineyard.

Since its invasion of the Mid-Atlantic region in 2010 and 2011, D. suzukii has become a significant pest of small fruits and softfleshed tree fruits (Walsh et al. 2011, Burrack et al. 2012). Some wine 
grape producers estimated losses above $80 \%$ for some varieties in which D. suzukii was detected (Carrington King, personal communication, 2012). Wine grapes are an economically important crop in Virginia, which was the nation's fifth largest wine grape producer in 2012, with 1,366 ha in production. A 2010 economic impact study estimated that the Virginia wine industry employs more than 4,700 people and contributes almost $\$ 750$ million to the Virginia economy on an annual basis (Frank et al., unpublished data). In 2013, Virginia ranked fifth in the number of wineries nationwide, with more than 222 in the Commonwealth (U.S. Winery Database 2013). More than 1.6 million tourists visited Virginia wineries in 2013, according to the Virginia Tourism Corporation and Virginia was in the top 10 wine tasting destinations in 2012 . Therefore, it is imperative to determine which varieties of wine grapes may be more susceptible to D. suzukii oviposition in order to protect the wine production and tourism industries in Virginia.

Wine grapes become susceptible to D. suzukii oviposition after véraison, with each grape variety ripening at different points during the growing season. During ripening, grapes undergo characteristic morphological and physiological changes associated with this process. Determining which grape varieties become susceptible to D. suzukii oviposition through morphological or physiological testing could determine which varieties are more susceptible and at a higher risk to $D$. suzukii oviposition. Those varieties that become susceptible earlier and at higher risk for infestation can then be more intensely managed. Wine growers may even choose to harvest earlier based upon fly pressure in the field if several varieties are about to become susceptible to $D$. suzukii oviposition. Wine growers may be able to more precisely determine varietal susceptibility to $D$. suzukii oviposition by using readily available tools such as a centi newton gauge, hand held digital calipers, and a refratometer. Our hypothesis is that there is no varietal difference in susceptibility to D. suzukii oviposition based upon morphological factors and that no D. suzukii will be able to complete development within these grapes. This study was undertaken to determine the physiological and morphological characteristics that make wine grape cultivars susceptible to D. suzukii oviposition, specifically skin thickness, skin penetration force, and ${ }^{\circ}$ Brix, and to evaluate the resulting adult emergence from the grapes.

\section{Materials and Methods}

The D. suzukii laboratory populations for these studies were from the offspring of adults collected from caneberry plantings in Montgomery County, Virginia during the summers of 2012-2015 and maintained on a commercially available medium, Nutri-Fly MF (molasses formulation) (Genesee Scientific Corporation, San Diego, CA). Six varieties of wine grapes, Vitis vinifera L., were used to evaluate varietal effects on D. suzukii oviposition and larval survivorship, including Petit Manseng, Petit Verdot, Vidal Blanc (hybrid: Ugni blanc x Rayon d'Or), Viognier, Cabernet Franc, and Pinotage. Field-collected clusters of each variety came from a single commercial vineyard in the Piedmont region (Orange County) of Virginia. All vineyard blocks received the same cultivation practices in regards to fertilization, weed management, fungicide, and insecticide applications. Leaves were also stripped from the fruit zone to enhance fruit quality. Weather data for the region was also collected (Supplementary Material). The vineyard block size from which grapes of each variety were collected was: Petit Verdot 0.65 ha, Cabernet Franc 1.07 ha, Pinotage 0.2 ha, and Vidal Blanc 0.75 ha, Viognier 0.3 ha, and Petit Manseng 0.3 ha. Six clusters were randomly collected from the middle of each grape varietal block at least three rows ( $>11 \mathrm{~m}$ ) away from the block edge and from the middle of the selected row $(>50 \mathrm{~m})$. The clusters had received standard applications of fungicides and insecticides, including captan, acetamiprid, clothianidin, spirotetramat, kaolin clay, and malathion. Clusters were placed in a cooler containing ice, avoiding direct contact with the ice, to prevent evapotranspiration of water from collected clusters. The clusters were then directly transported to Blacksburg for laboratory testing. If grapes were allowed to transpire after collecting, due to residual field heat, it may have influenced turgor pressure within the grapes and decrease penetration force accuracy. Testing of grape clusters began within $24 \mathrm{~h}$ of their collection from the field. Grapes used in ovipositional bioassay experiments were randomly selected and cut from the clusters using scissors; leaving the peduncle attached prevented access of D. suzukii adults to any exposed flesh created by removing the stem. Each year, laboratory assays were conducted over the course of several weeks during which grape physiological and morphological properties changed for each variety during the ripening process. While these changes may have affected ovipositional rates for the varieties tested, these experiments were an attempt to mirror grape physiological and morphological properties within the vineyard in which the grape varieties ripened at different rates. These grapes received standard insecticidal sprays; however, grape cluster collection was timed to avoid recent insecticidal sprays. Adult fly recovery after experiments further suggests that these insecticidal sprays did not influence mortality of the adults, eggs, or larvae in these experiments.

\section{Physiological and Morphological Characteristics}

Grapes undergo several physiological changes throughout the growing season. These changes were recorded for each experimental date by measuring the sugar content, skin thickness, and penetration force of 25 healthy, randomly-selected grape berries for each of the six grape varieties. ${ }^{\circ}$ Brix was determined by pressing the juice from a $20 \mathrm{~g}$ sample of randomly selected grapes of each variety and then placing the juice on a handheld, temperature-compensated refractometer (Zoro, Buffalo Grove, IL). Skin thickness (mm) was measured with a digital caliper (resolution $0.01 \mathrm{~mm}$, Mitutoyo, Kanagawa, Japan). Skin thickness measurements were achieved by inserting one caliper arm into the flesh of the grape at the equatorial midline and slowly closing the two caliper arms. Care was taken to not compress or cut through the grape skin while measuring the skin thickness. Several skin thickness training measurements using spare grapes from the same sample date for each variety were performed to develop a replicable technique using the digital calipers. Penetration force measurements (centi-newtons, $\mathrm{cN}$ ) were conducted using a technique adapted from Burrack et al. (2013), and involved placing a dulled \#2 insect pin (BioQuip Products, Rancho Dominguez, CA) on a piece of cork attached to a centi-newton gauge (Haag-Streit USA, Mason, $\mathrm{OH})$. The insect pin was dulled by running the point across an emery board that reduced the sharpness of the pin. Reducing the sharpness of the pin was done in an attempt to mimic a D. suzukii ovipositor in a laboratory setting. Measurements were performed with grapes still on the cluster in case pressure from neighboring grapes affected readings. Previous laboratory studies have excised individual grapes from the cluster before performing penetration tests and determined that berry position on the cluster and penetration point influence the skin-break force (Letaief et al. 2008). In our experiments, grapes were randomly selected from around the cluster to obtain a mean for all grapes in the cluster regardless of positioning. The pin was then pressed onto the equatorial midline of the grape at a $90^{\circ}$ angle to the skin until it punctured the surface of the grape. This positioning was kept the same for all grape berries 
tested for all testing dates and years. It is unknown if changing the penetration angle of the needle to the grape surface would increase or decrease the penetration force needed to puncture the skin, thus the $90^{\circ}$ angle was used for this experiment.

\section{D. suzukii Oviposition and Adult Emergence}

To investigate the effects of grape physiological characteristics on ovipositional preference and larval survivorship of D. suzukii on wine grapes, three laboratory-based experiments were performed: 1) no-choice trials using intact grapes, 2) no-choice trials using intact and manually damaged grapes, and 3) choice trials using intact grapes.

\section{No-choice trial using intact grapes 2014}

No-choice assays were conducted to compare differences in D. suzukii infestation rates between six wine grape varieties commonly grown in Virginia. Grapes for this experiment were collected on 27 August, 2, 9, and 16 September and experiments began within $24 \mathrm{~h}$ of their collection for each experimental harvest dates. Grapes were collected on these dates because all varieties had undergone véraison and were entering the ripening period. Grapes were checked for wounds under a dissecting microscope before the experiment; grapes with wounds were not used. No-choice tests involved placing $10 \mathrm{~g}$ of grapes from each of the six varieties in individual $355 \mathrm{ml}$ clear plastic cups (Solo, Urbana, IL). A constant mass was used to reduce effects of fruit size as adapted from Burrack et al. (2013). Fruit mass was standardized to ensure that all grape varieties had an equal amount of fruit present for female D. suzukii ovipositional choice. Grapes were weighed individually for each variety; so, an approximate number of grapes per variety could be determined. A quantity of $10 \mathrm{~g}$ was typically equivalent to 5-6 Viognier, 6-7 Cabernet Franc, 13-14 Petit Verdot, and 8-9 Pinotage, Petit Manseng, or Vidal Blanc grapes. Twelve rearing cups for each of the six grape varieties were used each week for four consecutive weeks after véraison (28 August to 16 September). Uninjured grapes were then placed in $355 \mathrm{ml}$ plastic rearing cups and five females and five males (between 0 and $14 \mathrm{~d}$ old) were added. Cups were covered with plastic wrap (Saran, Oakland, CA) and placed in a growth chamber at $23^{\circ} \mathrm{C}, 16: 8$ (L:D) and $50-80 \%$ RH. Flies were exposed to the grapes for $48 \mathrm{~h}$ and then removed from the cups. Individual grapes were examined under a dissecting microscope and eggs were counted. All grapes were then returned to the cups, covered with plastic wrap (Saran, Oakland, CA) and returned to the growth chamber. Rearing cups were checked daily for $21 \mathrm{~d}$ and any emerging flies were collected and counted. Laboratory assays were conducted over the course of $4 \mathrm{wk}$ in which grape physiological and morphological properties had changed for each variety, which may have affected ovipositional rates.

\section{Wine grape varietal susceptibility 2015}

During 2015, bioassays to determine the physiological and morphological point that each grape variety became susceptible to D. suzukii oviposition using uninjured and injured wine grapes were conducted. Experiments were also conducted to compare D. suzukii oviposition varietal preferences in injured and uninjured grapes. When grapes became susceptible to D. suzukii oviposition, the numbers of eggs as well as the number of adults emerging were counted for uninjured and injured grapes. The ovipositional rates and resulting adult emergence observations were conducted from 10 August to 31 August, which encompassed the period when grapes became susceptible to D. suzukii oviposition.

\section{Uninjured grapes}

Oviposition experiments in uninjured grapes were conducted for a total of $12 \mathrm{wk}$ (18 June to 9 September). Grapes were checked for wounds under a dissecting microscope before the experiment; grapes with wounds were not used. A replicate consisted of five uninjured grapes from each of the six varieties placed in individual $355 \mathrm{ml}$ clear plastic cups (Solo, Urbana, IL) on each experimental date. Five replicates per week of each grape variety were compared from the green pea stage (18 June) until véraison (20 July) when the replicates were increased to eight per week for each variety. Five females and five males (between 0 and $14 \mathrm{~d}$ old) were added, cups were covered with plastic wrap (Saran, Oakland, CA), and placed in a growth chamber at $23^{\circ} \mathrm{C}, 16: 8$ (L:D) and 50-80\% RH. Flies were exposed to the grapes for a 48-h period and then removed from the cups. Individual grapes were examined for oviposition wounds and eggs under a dissecting microscope and the date of the first oviposition was noted for each variety as well as the physiological characteristics of that grape variety at the time.

\section{Injured grapes}

Oviposition experiments were conducted using injured grapes for a total of 12 wk (18 June to 9 September). Grapes were checked for wounds under a dissecting microscope before the experiment; grapes with pre-existing wounds were not used. Three intact grapes were then pierced three times around the equatorial midline of the grape with pointed metal forceps. The wounds created by the forceps were 2-3 mm wide and $\sim 2 \mathrm{~mm}$ deep. Five male and five female D. suzukii flies (0-14 d old) were placed into a $355 \mathrm{ml}$ clear plastic cup with three injured grapes. Three replicates for each grape variety were performed weekly. Fruit were exposed to flies for a 48-h period and removed. Grapes were examined for oviposition wounds and eggs under a dissecting microscope and the date of first oviposition was noted as well as the physiological characteristics of that grape variety at the time of first oviposition.

\section{Oviposition and adult emergence 2015}

Once grapes became susceptible to D. suzukii oviposition (3 August) the number of eggs laid for each variety and grape condition were recorded. The experiments were conducted weekly between 10 and 31 August. The number of eggs laid for each variety and grape condition were counted using a dissecting microscope. After eggs were counted, all grapes were returned to the cups, covered with plastic wrap (Saran, Oakland, CA) and held for $21 \mathrm{~d}$ in a growth chamber at $23^{\circ} \mathrm{C}, 16: 8$ (L:D) and $50-80 \% \mathrm{RH}$. The grapes were checked daily by a visual inspection for any adults. Adults emerging were counted and collected from the plastic rearing cups, so an approximate number emerging from each grape variety and berry condition could be tabulated for each replicate.

Choice and no-choice trials using intact grapes 2013

No-choice and choice assays were conducted to compare differences in D. suzukii infestation rates between six wine grape varieties commonly grown in Virginia. Grapes for this experiment were collected from the field on 6, 14, and 22 September and experiments began within $24 \mathrm{~h}$ of their collection. Grapes were collected on these dates because all varieties had undergone véraison and were entering the ripening period. Grapes were checked for wounds under a dissecting microscope before the experiment, and grapes with wounds were not used. Cage no-choice tests involved placing a $20 \mathrm{~g}$ sample of individual grapes, cut off the cluster with pedicle attached, from one of the six varieties into $0.30 \mathrm{~m}^{3}$ collapsible mesh cages (BioQuip, Salinas, 
CA). A constant mass was used to reduce effects of fruit size. Grapes were weighed individually for each variety, so an approximate number of grapes per variety could be determined. A quantity of $20 \mathrm{~g}$ was typically equivalent to 10-11 Viognier, 13-14 Cabernet Franc, 26-28 Petit Verdot, and 17-18 Pinotage, Petit Manseng or, Vidal Blanc grapes. Fifteen male and 15 female D. suzukii flies (between 0 and $14 \mathrm{~d}$ old) were released into the center of the cages with grapes. Cages were placed on laboratory benches at room temperature of $23^{\circ} \mathrm{C}$ and exposed to indirect sunlight, $\mathrm{RH}$ was not measured. Cage positions on the benches were rerandomized for each experimental date. Grapes were exposed to flies for $4 \mathrm{~h}$, then the grapes were removed and placed in $355 \mathrm{ml}$ clear plastic rearing cups (Solo, Urbana, IL), covered with plastic wrap (Saran Wrap, Oakland, CA) and held in a growth chamber at $23^{\circ} \mathrm{C}, 16: 8$ (L:D) and 50-80\% RH. The number of eggs per grape was not counted. Cups were checked daily for $21 \mathrm{~d}$ and emerging flies were collected and counted. Twelve treatment replicates were run for each experimental date, with 3 experimental days in 2013. Choice experiments were performed using the same methodology as above using $20 \mathrm{~g}$ of each grape variety placed in a random arrangement within each cage. Eggs were not counted after the $4 \mathrm{~h}$ fly exposure period for the no-choice experiments. There were a total of 12 treatment replicates for each variety over the three experimental dates.

\section{Statistical Analysis}

Physiological characteristics for surface penetration force and skin thickness were analyzed using a full factorial ANOVA with testing dates (2013-2015) and wine grape variety as main effects. If interactions of grape variety and date were determined to be significant, each year was analyzed separately using one-way ANOVA, blocked by date, followed by Tukey's HSD to separate the means for the six grape varieties. Linear regression was used to examine the relationships between oviposition, skin thickness, and penetration force of the grapes for each experimental year. In 2013, choice cage tests using the six grape varieties were arranged in a completely randomized design within each cage, using the date of the experiment as a blocking factor. The $20 \mathrm{~g}$ grape samples for each variety were rerandomized within each cage for every experimental date. The ovipositional and adult emergence data for no-choice and choice tests for 2013, 2014, and 2015 for intact grape experiments could not be normalized, therefore a nonparametric Wilcoxon Test was used as well as a Wilcoxon Each Pair test to determine statistical significance. The 2015 injured grape oviposition preference and adult emergence data were analyzed using a one-way ANOVA, blocked by date, followed by Tukey's HSD to separate the means. Survivorship to adulthood in 2014 and 2015, using both uninjured and injured grapes, was analyzed using a mixed-model ANOVA (JMP SAS, Cary, NC) with grape variety as a fixed effect and replicate number within grape variety and experimental date as random effects.

\section{Results}

\section{Physiological and Morphological Characteristics}

All results in these experiments utilized grapes that had been previously refrigerated $(<24 \mathrm{~h})$, which were then utilized for physiological and morphological testing. There were significantly different penetration forces and skin thicknesses for all six grape varieties in all $3 \mathrm{yr}$ as well as a significant interaction between penetration force, skin thickness, and testing date (Table 1). Due to testing dates being significantly different, each experimental date for each year was analyzed separately. During the testing period, penetration force decreased, ${ }^{\circ}$ Brix increased, and skin thickness showed little variation for most grape varieties.

In 2013, while there were some differences as berries matured, Petit Manseng required the highest force to penetrate, while Viognier required the least (Table 2). In 2014 and 2015, Vidal Blanc and Petit Manseng required the most force to penetrate while Viognier required the least (Table 2). Skin thickness for all years tested did not show an overall decrease for all varieties over the ripening period (Table 3). In 2013, the thickest skin was shown to be Petit Manseng, while Petit Verdot had the thinnest. An increase in skin thickness on 23 September in the Pinotage and Petit Manseng compared to previous sample dates may be due to a rain event earlier in the week before sampling took place. This rainfall may have caused mesocarp tissue to expand which may have been inadvertently measured along with the hypodermal and epidermal cells. In 2014, Vidal Blanc had the thickest skin while Petit Verdot and Viognier had the thinnest. In 2015, Petit Manseng and Vidal Blanc possessed the thickest skin and Viognier the thinnest. Degrees Brix were tracked throughout the growing season and increased for most varieties over the testing period for each year. The exception to the increased soluble sugars within the grapes was seen on 23 September in 2013 when recent precipitation decreased the soluble sugars for most varieties within the grape berries (Table 4, Supplementary Table 1).

\section{No-Choice Trial Using Intact Grapes 2014}

The greatest number of eggs was laid in Viognier grapes and the fewest in Vidal Blanc (Table 5). The total number of adults emerging and the survivorship of eggs to adulthood were not significantly different among the six varieties. Significantly more eggs were laid when penetration force decreased (Fig. 1), but the correlation value was low $\left(R^{2}=0.033\right)$. There was no correlation between skin thickness and oviposition.

\section{Wine Grape Varietal Susceptibility 2015}

\section{Uninjured grapes}

Penetration force for the six grape varieties varied significantly by date over the 12 -wk period. No oviposition was observed during the first $6 \mathrm{wk}$ of testing of uninjured grapes. Uninjured grapes became

Table 1. Full factorial analysis for penetration force $(\mathrm{cN})$ and skin thickness $(\mathrm{mm})$ for six wine grape varieties, across all testing dates (years and weeks) combined

\begin{tabular}{|c|c|c|c|c|c|c|}
\hline & \multicolumn{3}{|c|}{ Penetration force $(\mathrm{cN})$} & \multicolumn{3}{|c|}{ Skin thickness $(\mathrm{mm})$} \\
\hline & $F$ & $\mathrm{df}$ & $P$ & $F$ & $\mathrm{df}$ & $P$ \\
\hline Date & 70.3854 & 10 & $<0.0001$ & 98.5465 & 10 & $<0.0001$ \\
\hline Grape Variety & 146.5846 & 5 & $<0.0001$ & 95.9302 & 5 & $<0.0001$ \\
\hline Date $\times$ Grape Variety & 8.0515 & 50 & $<0.0001$ & 9.9689 & 50 & $<0.0001$ \\
\hline
\end{tabular}


Table 2. Mean $( \pm \mathrm{SE})$ penetration force (centi-newtons, $c N)$ from 25 randomly selected grape berries representing six wine grape varieties exposed to Drosophila suzukii in choice $(2013)$ and no-choice bioassays $(2014,2015)$

\begin{tabular}{|c|c|c|c|c|c|}
\hline \multirow{2}{*}{$\frac{\text { Year }}{2013}$} & \multicolumn{5}{|c|}{ Experimental date $^{1}$} \\
\hline & Variety & 7 September & 14 September & 23 September & \\
\hline & Petit Manseng & $19.1 \pm 0.7 \mathrm{a}$ & $19.4 \pm 0.8 \mathrm{a}$ & $21.1 \pm 0.9 \mathrm{a}$ & \\
\hline & Vidal Blanc & $17.4 \pm 0.6 a b$ & $20.1 \pm 0.7 a$ & $17.0 \pm 0.5 b c$ & \\
\hline & Viognier & $14.9 \pm 0.4 b$ & $15.6 \pm 0.5 b$ & $13.5 \pm 0.6 \mathrm{~d}$ & \\
\hline & Petit Verdot & $15.6 \pm 0.7 b$ & $16.2 \pm 0.9 \mathrm{~b}$ & $15.6 \pm 0.6 \mathrm{bcd}$ & \\
\hline & Cabernet Franc & $15.6 \pm 0.58 b$ & $19.2 \pm 0.7 \mathrm{a}$ & $14.3 \pm 0.8 \mathrm{~cd}$ & \\
\hline & Pinotage & $16.6 \pm 0.7 \mathrm{ab}$ & $19.1 \pm 0.8 \mathrm{a}$ & $17.9 \pm 0.6 b$ & \\
\hline & $F$ & 5.7941 & 6.8029 & 16.7790 & \\
\hline & $P$ & $<0.0001$ & $<0.0001$ & $<0.0001$ & \\
\hline & $\mathrm{df}$ & 5,149 & 5,149 & 5,149 & \\
\hline & & 28 August & 3 September & 10 September & 17 September \\
\hline \multirow[t]{10}{*}{2014} & Petit Manseng & $18.2 \pm 0.6 a b$ & $17.0 \pm 0.8 \mathrm{ab}$ & $15.9 \pm 0.6 a$ & $16.9 \pm 0.7 \mathrm{a}$ \\
\hline & Vidal Blanc & $20.9 \pm 0.8 \mathrm{a}$ & $19.5 \pm 0.6 \mathrm{a}$ & $16.5 \pm 0.6 a$ & $14.9 \pm 0.3 a$ \\
\hline & Viognier & $12.8 \pm 0.7 \mathrm{~d}$ & $12.1 \pm 0.6 \mathrm{c}$ & $10.6 \pm 0.6 b$ & $10.4 \pm 0.6 b$ \\
\hline & Petit Verdot & $16.4 \pm 0.8 b c$ & $15.8 \pm 0.67 b$ & $11.2 \pm 0.6 b$ & $9.8 \pm 0.4 \mathrm{~b}$ \\
\hline & Cabernet Franc & $15.6 \pm 0.6 \mathrm{bcd}$ & $17.6 \pm 0.9 \mathrm{ab}$ & $11.7 \pm 0.5 b$ & $10.9 \pm 0.4 b$ \\
\hline & Pinotage & $14.8 \pm 0.7 \mathrm{~cd}$ & $16.2 \pm 0.7 b$ & $11.3 \pm 0.6 b$ & $10.1 \pm 0.4 b$ \\
\hline & $F$ & 16.0873 & 11.4257 & 20.3718 & 37.5043 \\
\hline & $P$ & $<0.0001$ & $<0.0001$ & $<0.0001$ & $<0.0001$ \\
\hline & $\mathrm{df}$ & 5,149 & 5,149 & 5,149 & 5,149 \\
\hline & & 10 August & 17 August & 25 August & 31 August \\
\hline \multirow[t]{9}{*}{2015} & Petit Manseng & $18.6 \pm 0.5 \mathrm{ab}$ & $17.9 \pm 0.3 \mathrm{ab}$ & $15.3 \pm 0.6 \mathrm{a}$ & $14.7 \pm 0.4 \mathrm{a}$ \\
\hline & Vidal Blanc & $19.6 \pm 0.6 a b$ & $17.5 \pm 0.4 a b$ & $15.2 \pm 0.3 a$ & $14.2 \pm 0.4 \mathrm{a}$ \\
\hline & Viognier & $10.8 \pm 0.6 \mathrm{~d}$ & $7.0 \pm 0.4 \mathrm{~d}$ & $10.0 \pm 0.3 b$ & $9.2 \pm 0.3 c$ \\
\hline & Petit Verdot & $17.9 \pm 0.6 b$ & $17.3 \pm 0.6 b$ & $14.1 \pm 0.4 \mathrm{a}$ & $11.2 \pm 0.3 b$ \\
\hline & Cabernet Franc & $20.8 \pm 0.7 \mathrm{a}$ & $19.6 \pm 0.6 \mathrm{a}$ & $11.0 \pm 0.4 b$ & $14.3 \pm 0.3 \mathrm{a}$ \\
\hline & Pinotage & $15.4 \pm 0.6 \mathrm{c}$ & $14.8 \pm 0.4 \mathrm{c}$ & $14.3 \pm 0.3 a$ & $13.8 \pm 0.4 a$ \\
\hline & $F$ & 36.0143 & 79.9381 & 37.5827 & 40.8402 \\
\hline & $P$ & $<0.0001$ & $<0.0001$ & $<0.0001$ & $<0.0001$ \\
\hline & $\mathrm{df}$ & 5,149 & 5,149 & 5,149 & 5,149 \\
\hline
\end{tabular}

${ }^{1}$ Values within a column followed by the same letter are not significantly different $(\alpha=0.05$, Tukey-Kramer adjustment).

susceptible to D. suzukii oviposition on 3 August 2015, with Viognier being the first attacked when its average penetration force was 16.15 $\mathrm{cN}$ (Table 6). Cabernet Franc had oviposition directly into the flesh 2 wk later (17 August 2015), when its average penetration force was $19.55 \mathrm{cN}$. Pinotage was the last grape variety to have eggs laid directly into the flesh (31 August 2015), with an average penetration force of $13.75 \mathrm{cN}$. Petit Manseng, Petit Verdot, and Vidal Blanc had no eggs laid directly into the flesh in uninjured grapes.

\section{Injured grapes}

The first egg laid on the manually injured grapes was on 18 June 2015 on Viognier $\left(5^{\circ}\right.$ Brix) and Cabernet Franc (5. $8^{\circ}$ Brix), with one and two eggs laid, respectively. Of those eggs laid on the Cabernet Franc, one adult emerged (data not shown). The average penetration resistance values for uninjured Viognier and Cabernet Franc were 32.9 and $24.35 \mathrm{cN}$, respectively (Table 6). Petit Manseng and Vidal Blanc had eggs laid on the injured grapes on 29 June with average penetration forces of 26.7 and $32.5 \mathrm{cN}$ in the uninjured grapes, respectively. Petit Verdot and Pinotage were the last to have eggs laid in the injured grapes ( $8 \mathrm{July}$ ) with an average penetration force of 20.6 and $28.2 \mathrm{cN}$ in the uninjured grapes, respectively. This indicated that D. suzukii females would lay eggs on unripe fruit in which the skin had been damaged.

\section{Oviposition and Adult Emergence 2015}

The Wilcoxon test showed that significantly more eggs were laid on uninjured Viognier and Cabernet Franc than on any other varieties
(Table 7). Few eggs were laid on Pinotage and no eggs were laid on the Vidal Blanc, Petit Manseng, or Petit Verdot grapes (Table 7). Grape varieties had significantly different average penetration forces (df $=5, F=66.6314 ; P<0.0001)$ with Viognier being the lowest, measuring $9.23 \mathrm{cN}$ (Table 7). The firmest varieties were Vidal Blanc and Petit Manseng and the thickest-skinned variety was Petit Manseng. Penetration force and oviposition in intact grapes were evaluated by a linear regression and found to be significant, however the $R^{2}$ value was low $\left(R^{2}=0.088\right)$ (Fig. 2). There was no linear correlation between skin thickness and oviposition. Survivorship was between 25 and $29 \%$ based upon variety, with significantly more D. suzukii surviving in Cabernet Franc and Viognier (Table 7).

The number of eggs laid in injured grapes was significantly different among the six varieties tested. The greatest numbers of eggs laid were in the Vidal Blanc and Pinotage grapes, with 15.8 and 11.2 eggs per replicate. The fewest eggs were laid on the Petit Manseng. Neither adult emergence nor survivorship (18-38\%) was significantly different among varieties (Table 7).

\section{Choice and No-ChoiceTrails Using Intact Grapes 2013}

There was no significant difference in the number of adult D. suzukii emerging among the six grape varieties in the choice tests (Table 8). There was no significant linear correlation between penetration force or skin thickness and number of adults emerging. There were also no significant differences in the number of adult D. suzukii emerging from the no-choice tests (Table 8). 
Table 3. Mean $( \pm \mathrm{SE})$ skin thickness $(\mathrm{mm})$ representing 25 randomly selected grape berries from six wine grape varieties exposed to Drosophila suzukii in choice (2013) and no-choice bioassays $(2014,2015)$

\begin{tabular}{|c|c|c|c|c|c|}
\hline \multirow[t]{2}{*}{ Year } & \multirow[b]{2}{*}{ Variety } & \multicolumn{3}{|c|}{ Experimental date $^{1}$} & \\
\hline & & 7 September & 14 September & 23 September & \\
\hline \multirow[t]{10}{*}{2013} & Petit Manseng & $0.16 \pm 0.005 \mathrm{ab}$ & $0.15 \pm 0.004 a$ & $0.21 \pm 0.011 \mathrm{a}$ & \\
\hline & Vidal Blanc & $0.17 \pm 0.009 a$ & $0.13 \pm 0.008 \mathrm{ab}$ & $0.13 \pm 0.008 b c$ & \\
\hline & Viognier & $0.13 \pm 0.006 c$ & $0.12 \pm 0.006 b c$ & $0.14 \pm 0.007 b c$ & \\
\hline & Petit Verdot & $0.10 \pm 0.004 \mathrm{~d}$ & $0.08 \pm 0.003 \mathrm{~d}$ & $0.09 \pm 0.004 \mathrm{~d}$ & \\
\hline & Cabernet Franc & $0.10 \pm 0.006 \mathrm{~d}$ & $0.11 \pm 0.007 c$ & $0.11 \pm 0.005 \mathrm{~cd}$ & \\
\hline & Pinotage & $0.14 \pm 0.005 b c$ & $0.14 \pm 0.005 \mathrm{ab}$ & $0.16 \pm 0.008 b$ & \\
\hline & $F$ & 23.1004 & 17.3075 & 31.8142 & \\
\hline & $P$ & $<0.0001$ & $<0.0001$ & $<0.0001$ & \\
\hline & $\mathrm{df}$ & 5,149 & 5,149 & 5,149 & \\
\hline & & 28 August & 3 September & 10 September & 17 September \\
\hline \multirow[t]{10}{*}{2014} & Petit Manseng & $0.11 \pm 0.004 \mathrm{ab}$ & $0.08 \pm 0.005 b$ & $0.14 \pm 0.006 \mathrm{a}$ & $0.16 \pm 0.005 \mathrm{a}$ \\
\hline & Vidal Blanc & $0.16 \pm 0.009 a$ & $0.11 \pm 0.005 a$ & $0.14 \pm 0.008 \mathrm{a}$ & $0.12 \pm 0.005 c$ \\
\hline & Viognier & $0.08 \pm 0.002 b$ & $0.06 \pm 0.004 \mathrm{c}$ & $0.09 \pm 0.004 c$ & $0.09 \pm 0.005 \mathrm{~d}$ \\
\hline & Petit Verdot & $0.07 \pm 0.004 b$ & $0.06 \pm 0.003 c$ & $0.07 \pm 0.002 \mathrm{~d}$ & $0.09 \pm 0.004 \mathrm{~d}$ \\
\hline & Cabernet Franc & $0.15 \pm 0.03 \mathrm{a}$ & $0.10 \pm 0.004 b$ & $0.11 \pm 0.003 b$ & $0.15 \pm 0.004 \mathrm{ab}$ \\
\hline & Pinotage & $0.13 \pm 0007 a$ & $0.09 \pm 0.004 b$ & $0.11 \pm 0.005 b$ & $0.13 \pm 0.004 b c$ \\
\hline & F & 8.0112 & 27.9790 & 30.2302 & 44.5660 \\
\hline & $P$ & $<0.0001$ & $<0.0001$ & $<0.0001$ & $<0.0001$ \\
\hline & $\mathrm{df}$ & 5,149 & 5,149 & 5,149 & 5,149 \\
\hline & & 10 August & 17 August & 25 August & 31 August \\
\hline \multirow[t]{9}{*}{2015} & Petit Manseng & $0.11 \pm 0.006 b$ & $0.09 \pm 0.004 b$ & $0.09 \pm 0.003 a$ & $0.08 \pm 0.004 a$ \\
\hline & Vidal Blanc & $0.14 \pm 0.005 a$ & $0.10 \pm 0.006 \mathrm{ab}$ & $0.06 \pm 0.005 b$ & $0.06 \pm 0.004 b c$ \\
\hline & Viognier & $0.05 \pm 0.005 c$ & $0.11 \pm 0.007 a$ & $0.07 \pm 0.005 b$ & $0.02 \pm 0.002 \mathrm{~d}$ \\
\hline & Petit Verdot & $0.10 \pm 0.004 b$ & $0.09 \pm 0.004 b$ & $0.04 \pm 0.002 c$ & $0.04 \pm 0.003 c$ \\
\hline & Cabernet Franc & $0.11 \pm .004 b$ & $0.09 \pm 0.004 b$ & $0.08 \pm 0.003 \mathrm{ab}$ & $0.06 \pm 0.003 b$ \\
\hline & Pinotage & $0.10 \pm 0.004 b$ & $0.10 \pm 0.004 b$ & $0.07 \pm 0.005 b$ & $0.05 \pm 0.003 b c$ \\
\hline & $F$ & 33.5571 & 3.9352 & 16.1847 & 37.9970 \\
\hline & $P$ & $<0.0001$ & 0.0025 & $<0.0001$ & $<0.0001$ \\
\hline & $\mathrm{df}$ & 5,149 & 5,149 & 5,149 & 5,149 \\
\hline
\end{tabular}

${ }^{1}$ Values within a column followed by the same letter are not significantly different $(\alpha=0.05$, Tukey-Kramer adjustment).

Table 4. Soluble solids ( ${ }^{\circ} \mathrm{Brix}$ ) of six wine grape varieties used in a study comparing oviposition by Drosophila suzukii, based on $30 \mathrm{~g}$ grape berry samples

\begin{tabular}{|c|c|c|c|c|c|}
\hline \multirow[t]{2}{*}{ Year } & \multirow[t]{2}{*}{ Grape variety } & \multicolumn{3}{|c|}{ Experimental date } & \\
\hline & & 7 September & 14 September & 23 September & \\
\hline \multirow[t]{7}{*}{2013} & Petit Manseng & 15.6 & 22.8 & 18.0 & \\
\hline & Petit Verdot & 15.4 & 20.4 & 16.0 & \\
\hline & Viognier & 19.2 & 23.2 & 21.8 & \\
\hline & Vidal Blanc & 16.0 & 16.0 & 15.0 & \\
\hline & Cabernet Franc & 13.2 & 16.2 & 19.2 & \\
\hline & Pinotage & 17.2 & 24.2 & 23.2 & \\
\hline & & 28 August & 3 September & 10 September & 17 September \\
\hline \multirow[t]{7}{*}{2014} & Petit Manseng & 14.8 & 20.2 & 21.4 & 23.8 \\
\hline & Petit Verdot & 11.9 & 12.8 & 17.6 & 16.2 \\
\hline & Viognier & 17.5 & 17.0 & 20.0 & 21.0 \\
\hline & Vidal Blanc & 14.5 & 19.8 & 20.0 & 21.0 \\
\hline & Cabernet Franc & 16.7 & 19.2 & 19.2 & 21.4 \\
\hline & Pinotage & 17.9 & 18.4 & 22.0 & 21.2 \\
\hline & & 10 August & 17 August & 25 August & 31 August \\
\hline \multirow[t]{6}{*}{2015} & Petit Manseng & 7.0 & 19.2 & 21.8 & 21.8 \\
\hline & Petit Verdot & 12.4 & 17.0 & 18.4 & 18.8 \\
\hline & Viognier & 14.0 & 17.4 & 19.0 & 23.0 \\
\hline & Vidal Blanc & 18.8 & 18.0 & 21.0 & 21.4 \\
\hline & Cabernet Franc & 11.0 & 15.0 & 19.0 & 19.0 \\
\hline & Pinotage & 21.2 & 22.0 & 20.6 & 24.0 \\
\hline
\end{tabular}


Table 5. Mean ( \pm SE) grape berry penetration force $(c N)$, Drosophila suzukii oviposition, adult emergence and egg to adulthood survival in laboratory no-choice bioassays in uninjured wine grapes $(10 \mathrm{~g})$ for all sample dates in 2014

\begin{tabular}{|c|c|c|c|c|}
\hline Variety & Penetration force ${ }^{1}(\mathrm{cN})$ & $\begin{array}{c}\text { D. suzukii eggs } \\
\text { laid }^{2}\end{array}$ & $\begin{array}{c}\text { Adult D. suzukii } \\
\text { emergence }^{2}\end{array}$ & $\%$ Survival $^{1}$ \\
\hline Petit Manseng & $17.0 \pm 0.4 a$ & $2.8 \pm 0.6 \mathrm{a}$ & $0.6 \pm 0.1$ & 11 \\
\hline Petit Verdot & $13.3 \pm 0.4 b$ & $3.1 \pm 0.8 \mathrm{a}$ & $0.7 \pm 0.2$ & 12 \\
\hline Viognier & $11.5 \pm 0.3 c$ & $4.8 \pm 1.3 a$ & $0.4 \pm 0.1$ & 9 \\
\hline Vidal Blanc & $17.9 \pm 0.4 a$ & $0.7 \pm 0.2 b$ & $1.5 \pm 0.4$ & 49 \\
\hline Cabernet Franc & $13.9 \pm 0.4 b$ & $1.1 \pm 0.5 b$ & $0.9 \pm 0.2$ & 28 \\
\hline Pinotage & $13.1 \pm 0.4 b$ & $3.6 \pm 0.6 \mathrm{a}$ & $1.0 \pm 0.2$ & 24 \\
\hline$F$ & 42.7375 & - & - & 2.1064 \\
\hline$P$ & $<0.0001$ & - & - & 0.0699 \\
\hline Prob > Chi-square & - & 0.0007 & 0.2678 & \\
\hline df & 5,149 & 5 & 5 & 5,110 \\
\hline
\end{tabular}

${ }^{1}$ Values within a column followed by the same letter are not significantly different $(\alpha=0.05$, Tukey-Kramer adjustment).

${ }^{2}$ Values within a column followed by the same letter are not significantly different $(\alpha=0.05$, Wilcoxon Each Pair Test).

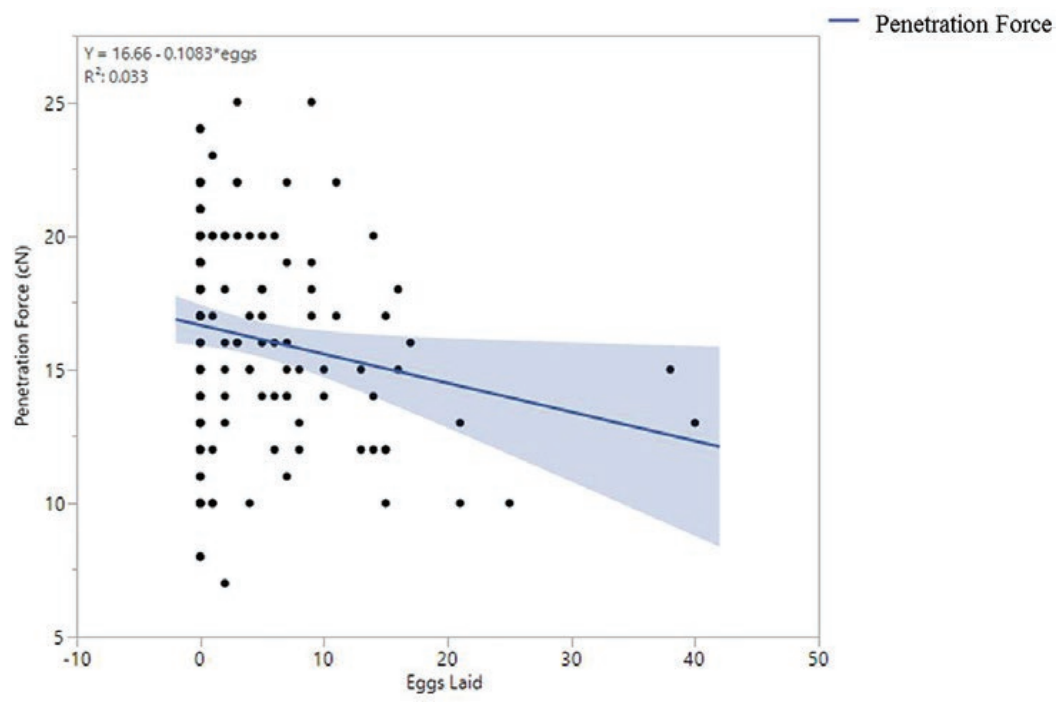

Fig. 1. Mean penetration force for all grape berries and resulting oviposition prevalence by Drosophila suzukii 2014.

\section{Discussion}

Testing in 2014 and 2015 demonstrated an ovipositional preference for Viognier, which also had the lowest penetration force. Linear regression performed in 2014 and 2015 demonstrated that oviposition increased in grapes with lower penetration forces, but the linear fit of the lines was poor. Our experimental observations were supported by previous similar studies showing more eggs laid in fruits when penetration forces decreased as well as no oviposition in grapes with high penetration forces (Lee et al. 2011b, Ioriatti et al. 2015). There was no linear relationship between skin thickness and penetration force nor was there a relationship between skin thickness and oviposition from comparisons in 2014 and 2015. These results enabled us to determine that $D$. suzukii risk of infestation was not based upon the skin thickness of the varieties. It had been expected that thin-skinned varieties would be more susceptible to D. suzukii oviposition. The choice and no-choice tests in 2013 showed no differences in adult emergence for any of the six varieties tested. These findings were similar to those of Lee et al. (2011a), when no significant difference was seen in ovipositional preference for four wine grape varieties.

The 12-wk uninjured grape susceptibility experiment determined that D. suzukii oviposition in grapes appeared to be based upon when each variety underwent véraison and began the ripening process. This was also the period during which the grapes began to sequester sugar. Thus, the early maturing grape varieties such as Viognier became susceptible to D. suzukii oviposition a month sooner than other varieties tested. The lack of oviposition seen in Vidal Blanc and Petit Manseng may have been due to the high penetration force of these varieties. Our laboratory findings suggested that physical factors could be used to determine which grape varieties within a vineyard might be at higher risk from D. suzukii oviposition. These measurements could be used to determine when peak susceptibility will occur for each variety as well as determine a varietal risk table for oviposition based upon ripening period (early or late), although laboratory findings are not always representative of what occurs in the field. Ioriatti et al. (2015) showed similar results with respect to penetration force and D. suzukii susceptibility when they observed that grape varieties with consistently high penetration force $(<40 \mathrm{cN})$ had no infestations of D. suzukii. However, the results of Pelton et al. (2016), working in Oregon, differed from our findings in that D. suzukii larvae were present in all grape varieties, regardless of penetration force in the vineyards surveyed, but at low presence and abundance $(15 \%)$ and that the likelihood of larval presence increased as the season progressed with no significant 
Table 6. abPenetration force $(\mathrm{cN})$ (mean $\pm \mathrm{SE}$ ) representing 25 randomly selected grape berries from six grape varieties exposed to a Drosophila suzukii oviposition bioassay in 2015

\begin{tabular}{|c|c|c|c|c|c|c|}
\hline Date & Cabernet Franc & Petit Verdot & Petit Manseng & Viognier & Vidal Blanc & Pinotage \\
\hline 18 -June $* *$ & $24.4 \pm 0.6 * *$ & $22.3 \pm 0.6$ & $27.0 \pm 0.5$ & $32.9 \pm 0.5 * *$ & $30.7 \pm 0.6$ & $31.3 \pm 0.6$ \\
\hline 29-June** & $25.3 \pm 0.7$ & $28.6 \pm 0.5$ & $26.7 \pm 1.1 * *$ & $26.6 \pm 0.8$ & $32.6 \pm 0.5 * *$ & $30.9 \pm 0.6$ \\
\hline 8-July** & $26.7 \pm 0.7$ & $20.6 \pm 0.6 * *$ & $28.6 \pm 0.5$ & $24.7 \pm 0.7$ & $29.4 \pm 0.9$ & $28.2 \pm 0.7^{* *}$ \\
\hline 13-July & $24.0 \pm 0.5$ & $22.9 \pm 0.6$ & $25.5 \pm 0.3$ & $22.9 \pm 0.06$ & $31.5 \pm 0.6$ & $24.9 \pm 0.4$ \\
\hline 20- July & $22.3 \pm 0.6$ & $20.3 \pm 0.6$ & $22.6 \pm 0.5$ & $24.9 \pm 0.7$ & $31.4 \pm 0.6$ & $24.3 \pm 0.4$ \\
\hline 27-July & $25.1 \pm 0.5$ & $18.8 \pm 0.4$ & $26.1 \pm 0.4$ & $12.4 \pm 0.4$ & $28.7 \pm 0.5$ & $18.2 \pm 0.5$ \\
\hline 3-Aug* & $24.2 \pm 0.8$ & $23.5 \pm 0.7$ & $25.3 \pm 0.6$ & $16.2 \pm 0.6^{*}$ & $20.1 \pm 0.6$ & $14.8 \pm 0.5$ \\
\hline 10-Aug & $20.8 \pm 0.7$ & $17.9 \pm 0.6$ & $18.6 \pm 0.5$ & $10.8 \pm 0.6$ & $19.5 \pm 0.6$ & $15.4 \pm 0.6$ \\
\hline 17-Aug* & $19.6 \pm 0.6^{*}$ & $17.3 \pm 0.6$ & $17.9 \pm 0.6$ & $7.0 \pm 0.4$ & $17.5 \pm 0.4$ & $14.8 \pm 0.4$ \\
\hline 25-Aug & $11.0 \pm 0.4$ & $14.1 \pm 0.4$ & $15.3 \pm 0.6$ & $10.0 \pm 0.3$ & $15.2 \pm 0.3$ & $14.3 \pm 0.3$ \\
\hline 31-Aug* & $14.3 \pm 0.3$ & $11.2 \pm 0.3$ & $14.7 \pm 0.4$ & $9.2 \pm 0.3$ & $14.2 \pm 0.4$ & $13.8 \pm 0.4^{*}$ \\
\hline 9-Sept & $11.1 \pm 0.3$ & $10.2 \pm 0.2$ & $13.8 \pm 0.5$ & $9.7 \pm 0.6$ & $13.9 \pm 0.3$ & $10.2 \pm 0.2$ \\
\hline
\end{tabular}

${ }^{a}$ Dates marked by * when direct oviposition occurred in intact grapes.

bDates marked by ** when direct oviposition occurred in injured grapes.

Table 7. Mean ( \pm SE) grape berry penetration force $(\mathrm{cN})$, Drosophila suzukii oviposition, adult emergence and egg to adulthood survival in laboratory no-choice bioassays from uninjured and injured wine grapes for all sample date in 2015

\begin{tabular}{|c|c|c|c|c|c|c|c|}
\hline \multirow[b]{2}{*}{ Variety } & \multirow[b]{2}{*}{$\begin{array}{l}\text { Penetration } \\
\text { force }^{1}(\mathrm{cN})\end{array}$} & \multicolumn{3}{|c|}{ Uninjured grapes } & \multicolumn{3}{|c|}{ Injured grapes } \\
\hline & & $\begin{array}{c}\text { D. suzukii eggs } \\
\text { laid }^{2}\end{array}$ & $\begin{array}{c}\text { Adult } D \text {. } \\
\text { suzukii } \\
\text { emergence }^{2}\end{array}$ & $\%$ Survival $^{1}$ & $\begin{array}{l}\text { D. suzukii } \\
\text { eggs laid }^{1}\end{array}$ & $\begin{array}{c}\text { Adult } D \text {. } \\
\text { suzukii } \\
\text { emergence }^{1}\end{array}$ & $\%$ Survival $^{1}$ \\
\hline Petit Manseng & $16.6 \pm 0.3 a$ & $0 \mathrm{~b}$ & $0 \mathrm{~b}$ & - & $3.9 \pm 1.8 b$ & $1.0 \pm 0.5$ & 26 \\
\hline Petit Verdot & $15.1 \pm 0.4 b$ & $0 \mathrm{~b}$ & $0 \mathrm{~b}$ & - & $7.3 \pm 1.3 \mathrm{ab}$ & $2.1 \pm 0.5$ & 28 \\
\hline Viognier & $9.2 \pm 0.26 c$ & $4.38 \pm 1.4 \mathrm{a}$ & $1.14 \pm 0.34 a$ & $26 a$ & $7.8 \pm 1.8 \mathrm{ab}$ & $2.5 \pm 0.6$ & 32 \\
\hline Vidal Blanc & $16.6 \pm 0.3 a$ & $0 \mathrm{~b}$ & $0 \mathrm{~b}$ & - & $14.5 \pm 2.9 \mathrm{a}$ & $2.6 \pm 0.8$ & 18 \\
\hline Cabernet Franc & $16.4 \pm 0.5 \mathrm{a}$ & $2.07 \pm 0.9 \mathrm{a}$ & $0.59 \pm 0.27 a$ & $29 \mathrm{a}$ & $6.2 \pm 1.9 \mathrm{ab}$ & $2.3 \pm 0.8$ & 38 \\
\hline Pinotage & $14.6 \pm 0.2 b$ & $0.14 \pm 0.1 b$ & $0.04 \pm 0.04 b$ & $25 \mathrm{~b}$ & $11.2 \pm 2.6 \mathrm{ab}$ & $3.0 \pm 0.9$ & 27 \\
\hline$F$ & 66.6314 & - & - & 6.4228 & 3.1163 & 1.0003 & 2.6618 \\
\hline$P$ & $<0.0001$ & - & - & 0.0070 & 0.0138 & 0.4246 & 0.0848 \\
\hline Chi-squared & - & $<0.0001$ & $<0.0001$ & & - & - & \\
\hline df & 5,149 & 5 & 5 & $2,20.1$ & 5,66 & 5,66 & $5,10.5$ \\
\hline
\end{tabular}

${ }^{1}$ Values within a column followed by the same letter are not significantly different ( $\alpha=0.05$, Tukey-Kramer adjustment).

${ }^{2}$ Values within a column followed by the same letter are not significantly different $(\alpha=0.05$, Wilcoxon Each Pair Test).

effect of variety. In the instance of Virginia wine grape production the earlier maturing varieties are at greater risk based upon the lower penetration force and the presence of $D$. suzukii adults already present in the landscape. D. suzukii have several wild host plants that can be readily found in and around wine grape vineyards in which these flies have been reproducing (Lee et al. 2015). These flies will then move into vineyards as grapes ripen, thus the earlier maturing varieties are at greater risk for initial $D$. suzukii oviposition than the later maturing varieties.

The intact grape oviposition assay further demonstrated that penetration force was a limiting factor for D. suzukii susceptibility in wine grapes. Our observations were substantiated by the injured grape experimental results. Observations from the 12-wk oviposition bioassay for injured grapes showed that oviposition would occur in grapes that were damaged despite low ${ }^{\circ}$ Brix. Furthermore, all grape varieties in this experiment had D. suzukii oviposit in wounds regardless of the level of soluble sugars ( ${ }^{\circ} \mathrm{Brix}$ ). Lee et al. (2011b) also demonstrated that D. suzukii could develop on strawberries with low ${ }^{\circ}$ Brix. D. suzukii laid more eggs in the injured grape varieties with higher ${ }^{\circ}$ Brix, but differences in egg numbers were not statistically significant. Every grape variety tested had adults emerge, but an increase in eggs laid did not result in more adults emerging. This suggested that there was a carrying capacity based upon grape variety. The overall suitability of grapes may have influenced survivorship as well; Bellamy et al. (2013) determined that grapes were a poor host for D. suzukii, which may have explained the low survivorship of eggs to adulthood within the grapes. Even with low oviposition rates per grape and low survivorship seen in our studies, there is still a risk for large amounts of $D$. suzukii to be produced in a vineyard. There may be millions of individual grapes in a given vineyard. Thus, there is the potential for a large population of D. suzukii to be produced within a wine grape production area as females can lay over 600 eggs in their lifetime (Emiljanowicz et al. 2014). Furthermore, grapes may be susceptible to cracking from rain events which negates grape berry skin penetration parameters and exposes grape flesh to the D. suzukii for immediate oviposition.

The fact that D. suzukii can utilize wine grapes as a host plant has a twofold impact on growers. First, when D. suzukii oviposit into grapes and adults emerge, the fly population could increase within the vineyard. D. suzukii populations in vineyards may also 


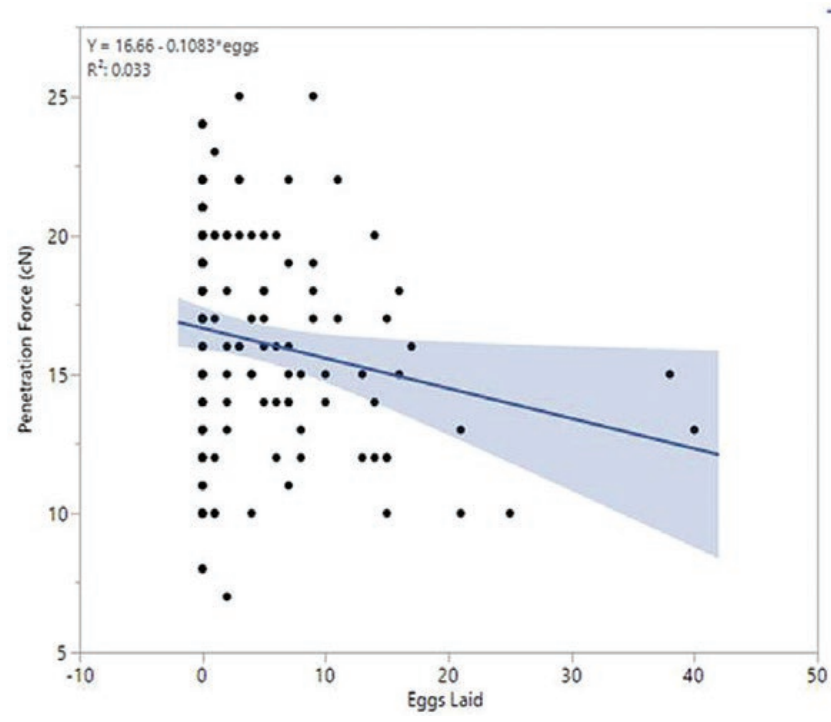

\section{Penetration \\ Force}

Fig. 2. Mean penetration force for all grape berries and resulting oviposition prevalence by Drosophila suzukii 2015.

Table 8. Penetration force $(\mathrm{cN})$ (mean $\pm \mathrm{SE}$ ) and adult Drosophila suzukii emergence (mean $\pm \mathrm{SE}$ ) from each experimental arena in laboratory choice and no-choice assays of six wine grape varieties for all sampling dates in 2013

\begin{tabular}{|c|c|c|c|}
\hline \multirow[b]{2}{*}{ Variety } & \multirow[b]{2}{*}{ Penetration force ${ }^{1}(\mathrm{cN})$} & \multicolumn{2}{|c|}{ Adult D. suzukii emergence ${ }^{2}$ from $20 \mathrm{~g}$ grapes } \\
\hline & & No-choice & Choice \\
\hline Petit Manseng & $19.9 \pm 0.5 \mathrm{a}$ & $0.9 \pm 0.4$ & $0.4 \pm 0.2$ \\
\hline Petit Verdot & $15.8 \pm 0.4 \mathrm{de}$ & $0.3 \pm 0.1$ & $0.8 \pm 0.4$ \\
\hline Viognier & $14.7 \pm 0.3 \mathrm{e}$ & $1.1 \pm 0.5$ & $0.8 \pm 0.4$ \\
\hline Vidal Blanc & $18.2 \pm 0.4 b$ & $0.06 \pm 0.1$ & $0.5 \pm 0.3$ \\
\hline Cabernet Franc & $16.4 \pm 0.5 \mathrm{~cd}$ & $0.4 \pm 0.2$ & $0.3 \pm 0.1$ \\
\hline Pinotage & $17.9 \pm 0.4 b c$ & $0.4 \pm 0.3$ & $0.6 \pm 0.2$ \\
\hline$F$ & 20.6976 & - & - \\
\hline$P$ & $<0.0001$ & - & - \\
\hline Prob $>$ Chi-square & - & 0.1319 & 0.6755 \\
\hline df & 5,149 & 5 & 5 \\
\hline
\end{tabular}

${ }^{1}$ Values within a column followed by the same letter are not significantly different $(\alpha=0.05$, Tukey-Kramer adjustment).

${ }^{2}$ Values within a column followed by the same letter are not significantly different (Wilcoxon Each Pair Test).

increase when flies utilize alternative host plants around the vineyards migrate into the vineyard blocks once grapes have ripened. Increased populations of D. suzukii are likely to injure more grapes. Second, the wounding of grapes by the serrated ovipositor of D. suzukii increases the likelihood of invasion by secondary pathogens, such as those causing sour rot, throughout the vineyard (Barata et al. 2012, Atallah et al. 2014, Rombaut et al. 2017). The whole cluster may be culled when only a few grapes have sour rot causing a loss of product and increasing management costs due to paying workers to cull clusters in the field. Growers in the Piedmont region suffered severe losses due to sour rot and one grower lost $80 \%$ of his Petit Verdot grapes to D. suzukii infestation. This pest is more burdensome to grape growers as opposed to other small fruit growers that can sort infested small fruits and berries, whereas grape growers must get rid of whole clusters if sour rot has been detected.

Based on our results, it appeared that Viognier is at the highest risk for oviposition early in the growing season than other later maturing varieties due to low penetration force needed to puncture the grapes. It was also an early maturing variety, which could make it a primary target for $D$. suzukii emigrating from areas around the vineyard, having developed on wild host plants. However, later maturing varieties (Cabernet Franc) may be at greatest risk of D. suzukii oviposition due to these grapes ripening later in the summer when D. suzukii populations are larger than those populations that occur in the spring. Determining which varieties are most susceptible and at highest risk of $D$. suzukii oviposition would help viticulturists plan what varieties to plant as well as design spray programs based upon physiological and morphological characteristics of each grape variety instead of spraying whole vineyards. This may decrease the management costs for these later maturing and harder fleshed varieties by eliminating unwarranted insecticidal sprays based upon the morphological and physiological state of the grapes.

\section{Supplementary Material}

Supplementary data are available at Journal of Economic Entomology online.

\section{Acknowledgments}

We thank the Virginia Wine Board for funding this research as well as The Horton Vineyard for the use of their vines. Thank you to Corey Reidel who 
helped perform this research, and to Chris Bergh, Kim van der Linde, and Jayesh Samtami, who reviewed an earlier draft of this paper. Thank you to Carlyle Brewster for his help with the statistical analysis.

\section{References Cited}

Atallah, J., L. Teixeira, R. Salazar, G. Zaragoza, and A. Kopp. 2014. The making of a pest: the evolution of a fruit-penetrating ovipositor in Drosophila suzukii and related species. Proc. Biol. Sci. 281: 20132840.

Barata, A., S. C. Santos, M. Malfeito-Ferreira, and V. Loureiro. 2012. New insights into the ecological interaction between grape berry microorganisms and Drosophila flies during the development of sour rot. Microb. Ecol. 64: 416-430.

Bellamy, D. E., M. S. Sisterson, and S. S. Walse. 2013. Quantifying host potentials: indexing postharvest fresh fruits for spotted wing Drosophila, Drosophila suzukii. Plos One. 8: e61227.

Burrack, H. J., J. P. Smith, D. G. Pfeiffer, G. Koeher, and J. Laforest. 2012. Using volunteer-based networks to track Drosophila suzukii (Diptera: Drosophilidae) an invasive pest of fruit crops. J. Integr. Pest Manag. 3: B1-B5.

Burrack, H. J., G. E. Fernandez, T. Spivey, and D. A. Kraus. 2013. Variation in selection and utilization of host crops in the field and laboratory by Drosophila suzukii Matsumara (Diptera: Drosophilidae), an invasive frugivore. Pest Manag. Sci. 69: 1173-1180.

Emiljanowicz, L. M., G. D. Ryan, A. Langille, and J. Newman. 2014. Development, reproductive output and population growth of the fruit fly pest Drosophila suzukii (Diptera: Drosophilidae) on artificial diet. J. Econ. Entomol. 107: 1392-1398.

Goodhue, R. E., M. Bolda, D. Farnsworth, J. C. Williams, and F. G. Zalom. 2011. Spotted wing drosophila infestation of California strawberries and raspberries: economic analysis of potential revenue losses and control costs. Pest Manag. Sci. 67: 1396-1402.

Hamby, K. A., and P. G. Becher. 2016. Current knowledge of interactions between Drosophila suzukii and microbes, and their potential utility for pest management. J. Pest Sci. 89: 621-630.

Ioriatti, C., V. Walton, D. Dalton, G. Anfora, A. Grassi, S. Maistri, and V. Mazzoni. 2015. Drosophila suzukii (Diptera: Drosophilidae) and its potential impact to wine grapes during harvest in two cool climate wine grape production regions. J. Econ. Entomol. 108: 1148-1155.

Kanzawa, T. 1939. Studies on Drosophila suzukii mats. Kofu, Yamanashi Agricultural Experiment Station.

Kim, M., J. Kim, J. Park, D. Choi, J. Park, and I. Kim. 2015. Oviposition and development potential of the spotted-wing drosophila, Drosophila suzukii (Diptera: Drosophilidae), on uninjured Campbell early grape. Entomol. Res. 45: 354-359.

Lee, J. C., D. J. Bruck, A. J. Dreves, C. Ioriatti, H. Vogt, and P. Baufeld. 2011a. In focus: spotted wing drosophila, Drosophila suzukii, across perspectives. Pest Manag. Sci. 67: 1349-1351.

Lee, J. C., D. J. Bruck, H. Curry, D. Edwards, D. R. Haviland, R. A. Van Steenwyk, and B. M. Yorgey. 2011b. The susceptibility of small fruits and cherries to the spotted-wing drosophila, Drosophila suzukii. Pest Manag. Sci. 67: 1358-1367.

Lee, J. C., A. J. Dreves, A. M. Cave, S. Kawai, R. Isaacs, J. C. Miller, S. Van Timmeren, and D. J. Bruck. 2015. Infestation of wild and ornamental noncrop fruits by Drosophila suzukii (Diptera: Drosophilidae). Ann. Entomol. Soc. Am. 108: 117-129.

Letaief, H., L. Rolle, G. Zeppa, and V. Gerbi. 2008. Assessment of grape skin hardness by a puncture test. J. Sci. Food Agric. 88: 1567-1575.

Pelton, E., C. Gratton, R. Isaacs, S. Timmeren, A. Blanton, and C. Guedot. 2016. Earlier activity of Drosophila suzukii in high woodland landscapes but relative abundance is unaffected. J Pest Sci. 89: 725-733. doi:10.1007/ s10340-016-0733-z.

Rombaut, A., R. Guilhot, A. Xuéreb, L. Benoit, M. P. Chapuis, P. Gibert, and S. Fellous. 2017. Invasive Drosophila suzukii facilitates Drosophila melanogaster infestation and sour rot outbreaks in the vineyards. R. Soc. Open Sci. 4: 170117.

U.S. Winery Database. 2013. Wine industry metrics. Available from https:// www.winesandvines.com/template.cfm?section=widc\&widcDomain=win eries\&widcYYYYMM=201311 (Accessed 1 September 2016).

Walsh, D. B., M. P. Bolda, R. E. Goodhue, A. J. Dreves, J. Lee, D. J. Bruck, V. M. Walton, S. D. O'Neal, and F. G. Zalom. 2011. Drosophila suzukii (Diptera: Drosophilidae): invasive pest of ripening soft fruit expanding its geographic range and damage potential. J. Integr. Pest Manag. 2: G1-G7. 